\title{
Revisiting the Complex Adaptive Systems Paradigm: Leading Perspectives for Researching Operations and Supply Chain Management Issues
}

\author{
Anand Nair* \\ Department of Supply Chain Management \\ Eli Broad College of Business \\ Michigan State University \\ East Lansing, MI. 48824 \\ Email: nair@broad.msu.edu
}

\author{
Felix Reed-Tsochas \\ Saïd Business School \\ University of Oxford \\ Oxford, OX1 1HP \\ Email: Felix.Reed-Tsochas@ sbs.ox.ac.uk
}

The authors are grateful for the insightful comments from the co-Editors-in-Chief and an anonymous reviewer in improving the paper.

February 2019

*Corresponding Author 


\title{
Revisiting the Complex Adaptive Systems Paradigm: Leading Perspectives for Researching Operations and Supply Chain Management Issues
}

\begin{abstract}
This paper introduces the articles that are part of this special issue and presents a conceptual model for a renewed consideration of the complex adaptive systems (CAS) perspective in operations and supply chain management research. A literature review identifies the approaches taken in published research to examine issues such as complexity, adaptation, and emergent behavior. We present a revised conceptual framework that offers directions for embracing key tenets from CAS research so as to gain deeper insights into pertinent issues within the field. We also propose some methodological directions that can help in undertaking rigorous investigations of some important aspects that have theoretical and managerial significance.
\end{abstract}

Keywords: Complexity, Adaptation, Emergent behavior, Nonlinear dynamics, Coevolution, Complex adaptive systems.

\section{Introduction}

In much of the research focusing on operations and supply chain management (OSCM) issues, we consider simplistic conceptions of organizational and inter-organizational structures, linear relationships between practices and performance, and ignore the adaptive nature of strategies and processes. OSCM, however, involves adapting to changes in complex global networks of organizations. Because organizations adapt and can exist in a complex environment with myriad relationships and interactions (Miller 
and Page, 2007), it is a natural step to situate OSCM issues within a complex adaptive systems (CAS) paradigm (Choi et al., 2001; Pathak et al., 2007; Nair et al., 2009). A CAS perspective makes it possible to incorporate increasing realism and empirical data into research models, making it more likely that these models can be understood in a practical business setting (Anderson, 1999). This increase in realism has been demonstrated across diverse application areas (VanWinkle, Rose, \& Chambers, 1993; Grimm, 1999; Grimm et al., 2005; Axtell, 2003; Epstein and Axtell, 2006), as well as the use of complex empirical data from business organizations (Nilsson \& Darley, 2006; Braha and BarYam, 2007; Saavedra, Reed-Tsochas and Uzzi, 2008; Saavedra, Reed-Tsochas and Uzzi, 2009).

As an example, in a paper published in Nature, Saavedra et al. (2009) built on stochastic models of interactions between species in an ecological setting and proposed a model that reproduces the overall bipartite structure of cooperative interactions between partnering species (i.e., plants and animals). The stochastic model uses simple specialization and interaction rules and successfully replicates the degree distribution ${ }^{1}$, nestedness $^{2}$, and modularity ${ }^{3}$ of not only pollination data sets in ecology, but also of organizational networks representing manufacturer-contractor relationships in the garment industry. Within the organizational and ecological bipartite networks, respectively, the specialization rule determines the number of partners each member of the manufacturer or the plant class cooperates with based on the reward value associated

\footnotetext{
1 If there are $\mathrm{p}_{\mathrm{k}}$ fraction of nodes in a network with $\mathrm{k}$ links then $\mathrm{k}$ refers to the degree and $\mathrm{p}_{\mathrm{k}}$ refers to the degree distribution (Strogatz 2001).

2 A nested pattern is one where the pattern of species in an area with fewer species is a proper subset of those in an area with more species (Patterson and Atmar 1986; Bascompte et al. 2003).

3 Network modularity measure how closely connected nodes are divided in modules (Olesen et al. 2007).
} 
with a member. The reward value, a function of the reward trait of the member, is influenced by external factors, such as geographic dispersion and population diversity. In organizational and ecological bipartite networks, based on the complementarity between the foraging traits of members of the contractor or the animal class (referred to as class A) and the reward traits of members of the manufacturer or the plant class (referred to as class $\mathrm{P}$ ), the interaction rule determines which members of class A cooperate with each member of class P. In OSCM, considering buyer-supplier relationships in terms of their bipartite structure and underlying structure in terms of degree distribution, modularity, and nestedness sheds new light into aspects of specialization and interaction among supply chain partners.

Recent advances extend models of organizational adaptation in complex combinatorial landscapes (Levinthal, 1997; Rivkin and Siggelkow, 2007) to complex production systems (Ethiraj and Levinthal, 2004; Ethiraj, 2007). Addressing the questions of adaptability in individual organizations can contribute to OSCM theory and practice by embracing aspects of complexity, adaptation, and systems thinking, as has been demonstrated for manufacturing strategy (Levinthal and Warglien, 1999), supply base management (Choi \& Krause, 2006), and manufacturing network relationships (Lomi and Patterson, 2007).

This special issue aims to offer empirically grounded, interdisciplinary insights related to incorporating complexity, adaptation, and systems thinking into OSCM theory. In the next section, we review prior research applying a CAS perspective in OSCM. In the third section, we offer some refinements and extensions to the model presented in Choi et al. (2001), which has guided CAS-focused research in the OSCM domain. The 
fourth section presents our revised framework. In the fifth section, we introduce the five articles in this special issue and highlight how they relate to our proposed framework. Finally, in the sixth section, we offer theoretical and methodological directions for future research.

\section{Taking stock of the Complex Adaptive Systems (CAS) Perspective}

Choi et al. (2001) developed a framework that positions supply networks as a kind of CAS and offers directions for considering various facets. This framework emphasizes three key concepts. The first concept is internal mechanisms that represent the rules or schemas that socially embedded agents use to make decisions. Agents (entities) and schema, self-organization and emergence, network connectivity, and network dimensionality comprise the key elements of internal mechanisms. The second key concept is the external environment to which those decision-making agents respond. Specifically, changes in the environment cause CAS to exhibit dynamism. Agents respond to the changing environment and react to other agents' actions. The third concept is coevolution that characterizes the nonlinear changes in schemas, network connectivity, network dimensionality, and the external environment that result from their decisions. The changes made by the agents in responding to the environment cause further changes to the environment, thereby causing the agent and the environment to coevolve. The framework laid the foundation for several subsequent studies that use a CAS perspective to examine supply chain management issues.

To understand the extent of coverage of the CAS perspective in the field, we review the literature published in leading OSCM journals. We identified all the articles 
whose abstracts contained one or more of the following search criteria: "complex" OR "complexity" OR “emerge" OR "evolution" OR "adapt" OR "adaptation" OR "adaptive" OR "emergence" OR "systems theory" OR "network science". Next, we downloaded these papers and used NVIVO to analyze their full text. Table 1 summarizes the results of this search process:

Table 1: Summary of references to elements of CAS

\begin{tabular}{|c|c|}
\hline Journal & Number of papers \\
\hline $\begin{array}{c}\text { Journal of Operations } \\
\text { Management }\end{array}$ & 127 \\
\hline $\begin{array}{c}\text { Production and Operations } \\
\text { Management }\end{array}$ & 140 \\
\hline $\begin{array}{c}\text { Manufacturing and Service } \\
\text { Operations Management }\end{array}$ & 19 \\
\hline $\begin{array}{c}\text { Journal of Supply Chain } \\
\text { Management }\end{array}$ & 41 \\
\hline $\begin{array}{c}\text { Journal of Business } \\
\text { Logistics }\end{array}$ & 42 \\
\hline Decision Sciences* & 160 \\
\hline Management Science* & 447 \\
\hline Operations Research* & 395 \\
\hline Total & $\mathbf{1 3 7 1}$ \\
\hline
\end{tabular}

*Note: Given the interdisciplinary nature of the journal, many articles are not related to operations management or supply chain management.

Our review suggests that the consideration of issues such as complexity and adaptive and emergent behavior have mainly been limited to examination of networkrelated issues in the supply chain management domain (Choi and Hong 2002; Choi and Krause 2005; Kim et al. 2011; Kim et al. 2014; Pathak et al. 2014; Giannoccaro et al. 2018). For instance, Choi and Hong (2002) framed the structure of a supply network in three dimensions—-formalization, centralization, and complexity. Choi and Krause (2005) focused on the supply base and examined complexity therein as a key managerial 
consideration, operationalizing it in terms of three dimensions: (1) the number of suppliers in the supply base, (2) the degree of differentiation among these suppliers, and (3) the level of interrelationships among the suppliers. Kim et al. (2011) demonstrated the use of social network analysis to investigate the structural characteristics of supply networks and emphasized that the relative structural position in the network determines the roles of individual supply network members. Choi et al. (2012) simulated a system dynamics model to examine postponement strategy in the context of the global production-distribution system of an automobile manufacturer. Kim et al. (2014) showed the importance of differentiating a node/arc disruption versus a network disruption and demonstrated that node- or arc-level disruptions do not necessarily lead to network-level disruptions. Pathak et al. (2014) employed interrelated dimensions of ties between firm, firm-level task, network-level objective, and governance to develop four supply network archetypes and explained the evolution of coopetitive relationships. Lang et al. (2014) applied an NK landscape model of a multi-plant manufacturing network and analyzed how knowledge transfers within the network.

While the contextual focus of the framework presented in Choi et al. (2001) has helped position the CAS perspective for the study of networks in the OSCM domain, other areas of research have remained detached from the developments in the CAS paradigm. The literature review highlights a wide range of scholarly perspectives on complexity. A dominant approach is to conceptualize environmental complexity (Azadegan et al. 2013; Gligor et al. 2014) and task complexity (Fransoo and Wiers 2005; Handley and Benton 2013; Tenhiälä 2010) stemming from roots in the theory of organizational design. Additionally, researchers have considered aspects of business 
diversification (Williams et al. 2016), globally dispersed and multi-tiered nature of supply chains (Wilhelm et al. 2015); operational scope characterized in terms of component, coordinative, and dynamic complexities (Bozarth et al. 2008; Kovach et al. 2015); historical and contextual information (Seifert et al. 2015); vertical, horizontal, and spatial complexity in upstream supply chains (Bode and Wagner 2014; Bozarth et al. 2008; Vanpoucke et al. 2014); product complexity (Closs et al. 2008; Jacobs and Swink 2011); and interdependencies (Matos and Hall 2007; Verma et al. 2011).

A very small set of studies have explicitly considered the notion of complexity and adaptation as developed in the CAS perspective. As a notable exception, Ramasesh and Browning (2014) integrated complexity theory and the sociological theories of normal accidents and high reliability organizations to propose a conceptual framework to manage knowable unknown unknowns in projects. The study conceptualized complexity in terms of element and relationship complexities. In the study, complicatedness relates to "cognitive complexity." The authors identified six factors that drive complicatedness: lack of encapsulated interactions, lack of observer capability, unintuitive system organization, lack of observer experience (novelty), very large scale-up, and divergent viewpoints.

As with studies of complexity, studies of adaptive behavior in the OSCM context also lack connection with the knowledge base presented by the CAS perspective, barring a few exceptions. Browning and Ramasesh (2007) considered adaptability as a foundation for building three propositions for developing process models of product development projects. Holweg and Pil (2007) evaluated the interactions between information, physical flow, and supply chain evolution. Their study examined the 
applicability and complementarity of the resource based view, CAS perspective, and adaptive structuration theory and proposed an adaptive systems theory. Behavioral studies in OSCM have started to account for adaptive and purposeful human agents (Tangpong et al. 2014; Urda and Loch 2012). Some studies have considered emergent properties in OSCM (Altay and Pal 2014; Browning and Heath 2009; Tangpong et al. 2014; Narasimhan et al. 2009; Nair et al. 2011; Giannoccaro et al. 2018). However, there is a need for additional research to gain a better understanding of the phenomena.

\section{Looking Ahead with a Revised Framework}

To help position the CAS perspective for examining issues beyond those pertaining to supply networks, we revisit the conceptual foundation presented in Choi et el. (2001).

\subsection{Constituents of a Complex Adaptive System}

Choi et al. (2001) considered internal mechanism, environment, and co-evolution as the three foci for studying CAS. Agents, self-organization, emergence, connectivity, and dimensionality were considered to be part of the internal mechanism. Environment was characterized by dynamism and rugged landscape, while quasi-equilibrium and state change, non-linear changes, and non-random future characterized co-evolution. Within this representation, we believe that there is a conflation between what a CAS is and how one should model it. For instance, as a part of the internal mechanism, Choi et al. (2001) noted that agency, defined as "the ability to intervene meaningfully in the course of events" (Choi et al. 2001; p. 353), is an essential characteristic of a CAS. This feature of an agent is used to distinguish a complex system (such as a water molecule) from a CAS (such natural and living systems). However, studies focusing on complex adaptive 
matters show that emergent behavior can appear in many guises without an apparent agency in the underlying fundamental particles that make up the matter (Laughlin and Pines 2000). In fact, according to Lehn (2013), within chemistry (the example that is presented in Choi et al. 2001), there is an evolution “...from molecular to supramolecular to become adaptive chemistry by way of constitutional dynamics, which allow for adaptation, through component selection in an equilibrating set" (emphasis added) (pp. 2837).

Since agents can themselves have rules and meta-rules (i.e., rules that they use for learning) (Schelling, 1971), placing agents within the internal mechanism presents some theoretical issues. Specifically, it is unclear how one should account for the internal mechanisms within agents (referred to as schema in Choi et al. 2001). We assert that schemata are a very particular subset of CAS and they represent the rule system within the agent as well as within the environment. Any system can be conceptualized to consist of a population of rules, a structure of rules, and a process of rules. Dopfer et al. (2004) referred to this rule system as "meso" and asserted that evolution does not result in a movement from a micro state to a macro state. Instead, micro-meso-macro is an appropriate analytical structure for studying evolutionary systems. The authors asserted, "The essential point to grasp here is that macro is not a behavioural aggregation of micro, but, rather, it offers a systems perspective on meso viewed as a whole. Similarly, micro is not the reduced essence of an economic system; it is a 'bottom up' systems perspective on meso when viewed in terms of its component parts. The economic system is built upon meso; micro and macro are two perspectives that reveal the structural aspects of the 
changes in the meso populations that constitute the elementary units of the economic system" (p. 267).

To perform effectively, complex adaptive operational and supply chain systems rely on organizational memory to accumulate, store, retrieve, and use information about crucial aspects of the environment. Since all instances of environmental variability, interaction, or impact throughout the experience of the operational system cannot be recorded or processed, the organizational memory (except for random experiences) is compressed into schemata that organize and codify the system's experience into a model (Gell-Mann 1992, 2002; Holland, 1995; van der Leeuw et al. 2000). Within the area of OSCM, these schemata can take a variety of forms such as relational norms, organizational culture, planning and information systems, and other organized elements. Additionally, studies have found that populations of agents can evolve at different time scales. To account for this, it is important to consider explicitly slow and fast evolutions of time-scales in the study of CAS. For instance, to study OSCM issues one needs to take into consideration the industry as a CAS within which a firm is operating. Industries could evolve at different time scales due to the changes in the core activities and/or changes in the core assets (Fine 2000; McGahan 2004). On the one hand, core activities evolve at different rates depending on their relevancy to supply chain partners and customers in the presence of other alternatives. On the other hand, core assets such as resources, knowledge, and brand capital evolve at a certain rate depending on their contribution in generating value. Some industries, such as the paper industry, have evolved relatively slowly whereas others, such as the computer industry, have exhibited fast evolution. In fact, an industry can go through different rates of evolution during 
different time-periods. For instance, with its movement towards connected cars with advanced features such as cloud computing, big data, and the Internet of Things (IoT), the automotive industry is witnessing a much faster rate of change since 2016 as compared to its rate of evolution previously. These time-scales influence the underlying rules governing agent behavior as well as the environment, thereby presenting non-trivial implications for their co-evolution.

The adaptive behavior of organizations in light of the changing industrial and technological environment could be compared with idea of "Red Queen effect" that has been reported in ecological studies. It refers to the continued adaptation of species due to the interaction of population (biomass) dynamics and mutation (trait) dynamics (van Valen 1973). As compared to the chaotic, continued adaptation presented by the Red Queen effect, the other end of the spectrum is that of an "evolutionary stable strategy" where species do not change their survival strategy as long as other organisms also maintain their current strategy. Real ecosystems are characterized by conditions that fall between the chaos resulting from the Red Queen effect and the ordered regime of evolutionary stable strategy (Kauffman and Johnsen, 1991). Similarly, organizations also operate in this regime between complete chaos and complete order where their fitness can be improved by careful selection of alternatives. Studies in the OSCM domain that examine issues such as 'tradeoffs' and 'focus' have offered useful insights into the consideration of alternatives; however, an explicit investigation of the level of evolution and dynamism in the environment, and the consequent implications for the adoption of appropriate tactics and strategies is lacking. A CAS-based framing may help unravel new 
insights relating to coevolution of organizational, operational, and supply chain strategies in changing environments.

Considering the aspect of environment, Choi et al. (2001) noted that it " “...exists external to the CAS and consists of agents and their interconnections that are not part of the given CAS" (p. 355). It is unclear why the environment should be external to the CAS and consist of agents. For instance, if one is part of a project team and interacting with other teams, should these other teams be represented as an 'agent'? We believe that with the level of interconnectedness due to the advancement in technologies and owing to the dynamic interactions among such varied systems as economy, environment, globalization, infrastructure, health, education, and human development, the distinction between the system and the environment is not self-evident. Given the level of interconnections and interrelationships, is it necessarily true that the environment is external to what constitutes the CAS?

Consistent with Simon $(1992,2000)$, we propose a change in the perspective such that agents and environment together form the CAS. This conceptualization is in concert with prior studies that have considered environment as a part of the system (Shapiro 1964; Alderson 1965; Kadirov and Varey 2011). Shapiro (1964) argued that the environment is part of the system rather than being outside of the system. To set appropriate boundary conditions for investigation, he proposed the notion of "the relevant environment" (p. 120). Alderson (1965) developed a typology that characterized environment in terms of proximate environment, aspiration environment, and the ultimate environment. Ludwig Von Bertalanffy, one of leading founders of the general systems theory, claimed that, "The spatial boundaries of even what appears to be an obvious 
object or "thing" actually are indistinct... it is difficult to tell what belongs to the living system and what does not. Ultimately all boundaries are dynamic rather than spatial" (Von Bertalanffy 1972, p. 422). The dynamic boundary of a system can be thought of as an active interpretation of the environment based on the behavior and the schemata of system agents. The change in the environment is interpreted within the CAS and contributes towards consequent sensemaking through perceptions, interpretations, and actions (Daft and Weick 1984; Thomas et al. 1993). As a result of the actions, the enacted environment is also co-created within the CAS. We believe that a categorization of environment that distinguishes the "interpreted and enacted environment" from the external environment is necessary to scope the boundary of a CAS.

\subsection{Nature of co-evolution}

Considering environment to be outside the CAS, Choi et al. (2001) noted that coevolution is a result of this external environmental influence. However, research in CAS has shown that co-evolution does not have to be environmentally driven. In a predatorprey model, the co-evolution is due to internal dynamics (Dieckmann and Law 1996). Through repeated interaction, dynamism can result without environmental influence (Arthur 1995). In the same vein, Choi et al. (2001) emphasized that quasi-equilibrium characterizes the co-evolution observed in complex systems. However, recent studies have shown that some complex systems have the property of quasi-equilibrium and others do not (Halstrom and Galle 2015; Jokela 2010). Choi et al. (2001) referred to the notion of the "edge of chaos," whereby complex systems will be in a balanced state between complete order and complete disorder. Recent studies in complex systems have shown that such punctuated equilibrium does not occur in all instances and requires a 
specific network structure to manifest fully. Specifically, it requires some level of balance between the number and magnitude of agent interactions (Wosniak et al. 2017). A deeper examination of situations within the OSCM domain that are characterized by this balance and those that are not is necessary to embrace the concept fully.

Choi et al. (2001) noted that self-organization of supply networks occurs in a nonlinear fashion due to the overlapping complex structures and interdependencies between organizations. While facets of complexity and interdependencies can result in non-linear dynamics, some additional, fundamental issues can aid in a fuller consideration of nonlinear dynamics within the OSCM area. Complex behavior can arise in a deterministic, nonlinear, dynamic system as long as it exhibits properties such as strange attractors, sensitive dependence on initial conditions, and a characteristic structure (Ruelle 1980). Attractors refer to states that a system gravitates to and around which it cycles unless perturbed. Within chaotic systems, strange attractors bring predictability by creating a basin of attraction for all the underlying microstates of the system (Lee 1997; Dooley and Van de Ven 1999). Consideration of these issues may shed newer insights into, for instance, how buying organizations should work with startup suppliers who present a context that is very different from that of established suppliers. In such situations, supply managers need to consider the initial conditions and underlying characteristics of the buyer-supplier relationship. In addition, sourcing managers need to steer the relationship in a mutually beneficial direction by taking a holistic view of the overall supply base, the product life cycle, and the role of technology provided by the startup suppliers within this ecosystem (Wagner et al. 2017). In essence, by reimagining their role, a supply manager acts as a strange attractor by limiting the degrees of freedom 
of the supplying agent, ensuring different initial conditions are sampled, and increasing interdependencies in the early stage (Levinthal \& Warglien, 1999; Boal and Schultz 2007).

Nonlinear dynamics cause interesting behaviors in nature such as eddies in creeks, weather patterns, and vortices around marine invertebrates. Changes in parameters of these nonlinear systems bring about qualitative changes (i.e., bifurcations) in the dynamics (e.g., the effect of the change in water level on an eddy in a creek, the change in blood chemicals on the functioning of brain, etc.). Within OSCM research, studies of the bullwhip effect have tapped into some of the underlying aspects of nonlinear dynamics. However, in most cases these investigations have been limited to simulation and qualitatively understanding the nature of complexity in the system. Investigations using Lyapunov's exponent (nonlinear analogs of eigenvalues), a useful analytical concept for characterizing attractors, are quite scarce in the OSCM literature (some notable exceptions include, Hwarng \& Xie 2008; Jayanthi and Sinha 1998; Smunt and Ghose 2016) and offer important directions for more fully understanding the phenomenon of nonlinear dynamics in OSCM.

\subsection{Embracing complexity}

Weaver (1948) identified that the notion of complexity has gone through successive historical emergence. In the $17^{\text {th }}$ to $19^{\text {th }}$ centuries, complexity was handled with the tools of classical physics. Using deterministic assumptions, quantitative data was used to obtain objective and causal explanation of the underlying phenomenon. According to Weaver (1948), the second phase of conceptual development dealt with the problems of "disorganized complexity." Relaxing the assumption of certainty that underpins the 
developments until $19^{\text {th }}$ century, this phase used statistics and probability theory to examine disorder as an integral part of natural phenomena, such as entropy in thermodynamics and discontinuity in quantum mechanics. While this development enabled our understanding of several phenomena, Weaver noted that this approach is unable to account for situations that lack a sufficient level of disorder and predicted that, in the future, the focus will turn to "organized complexity," where the number of variables will be moderate (not very small or large in number), thereby limiting the ability to use the law of large numbers. Additionally, the defining characteristic of complexity in these problems is that it shows the essential feature of organization. Organized complexity captures kinds of organization in the form of structure, pattern, and regularity. Over the course of seven decades since Weaver's prediction, theoretical development of complexity has gone through successive stages of development spanning different paradigms (Alhadeff-Jones 2008).

Recent experimental and theoretical studies have developed measures that can help in calculating, estimating, and interpreting the notion of complexity. For example, using the concepts from complex systems, Li et al. (2008) mapped the number of different possible conformations (landscapes) that a long-chain protein molecule can adopt. The authors used network analysis and information theory to resolve the degeneracy of structurally distinct physical states, finding that measuring the structural complexity of a protein's conformational fluctuations gave new insight into the memory that proteins store. Along the same line, consideration of structural complexity (say, of supply network or operational teams) and the associated, inter-organizational knowledge/memory that is preserved in these structures offers pathways towards deeper 
understanding of the nature of complexity within the OSCM domain that links with network analysis and information theory.

Studies have also analytically revealed that complexity measures fall under the rubric of communication and computation theories. Shannon's information theory provides the basis for breaking a system's organization into degrees of information storage and degrees of communication capacity, and to monitoring the extent to which these are present but encrypted in a system's behavior (Crutchfield 2012). Within the OSCM area, Seifert et al. (2015) investigated how the information from historical and contextual predictors differentially influenced human forecasters' ability to detect and exploit linear and nonlinear cue-criterion relationships in the task environment. However, studies considering the role of information in conceptualizing complexity are rare. Consideration of aspects of organized complexity and the information theoretic underpinnings of complexity offer important directions for clearly conceptualizing and studying complexities faced by operations and supply chain managers.

Studies, including ones in the OSCM domain, have proposed that complexity in a network can be measured by the density of ties (May, 2001; Kim et al. 2011). May (2001) noted that if we assume a food web to be a random network, then the instability of the network increases with its density. However, it is now well known that random networks are a poor representation of several real-world networks (Barabási and Albert 1999) and, further, it can be reasoned that all agents and connections between agents may not matter equally in the network (Brock et al. 1998; Barrat et al. 2004; Cilliers 2002; May et al. 2001; Wang et al. 2004). Given that studies in the OSCM area have shown that random networks are not an appropriate representation of supply networks (Basole and 
Bellamy 2014; Nair and Vidal 2011), there are important implications for theory development pertaining to the complexity of networks commonly witnessed in the context of OSCM. It is important to consider complexity more broadly to cover aspects such as modularity, specialization, and other structures at the mesoscopic level (Papo et al. 2014). Barring a few exceptions (e.g., Ramasesh and Browning 2014; Yan et al. 2015), studies considering supply network connectivity have not accounted for the diversity of ties that organizations have to deal with. We simplify it by considering the connectivity as dense or sparse. When environment is viewed as a part of the system, this diversity of connections can be considered as a representation of the environment, which now can be examined with the help of new techniques such as Shannon-Jensen divergence analysis (Rosso et al. 2013).

\section{Guiding Framework}

Figure 1 presents our conceptual model for a renewed consideration of the CAS perspective in OSCM research. We believe that a CAS should be considered in terms of both its agents and the environment. The interactions between agents and the environment leads to emergent system properties, and the emergent system properties, in turn, influence the agents and the environment. As for the level of specifications within this model, following Schelling (2006), we believe that agents can be considered fairly unambiguously in terms of micro-specifications. Agents are characterized in terms of their attributes, behavior, and degrees of freedom. The degrees of freedom capture the idea of dimensionality as presented in Choi et al. (2001) and refer to the ability of an agent to act in an autonomous fashion. We avoid the term "dimensionality" so as to avoid 
confusion with the dimensionality of the environment. In addition, the conceptual block "Agents" covers aspects such as the level of heterogeneity among agents in the population, the level of connectivity among agents, the learning capacity of agents, and consideration of whether the agent is static or dynamic.

While environment is typically macro-specified, we assert that, depending on how we make the distinction between agents and environment, it is not self-evident that the environment is entirely macro. For example, some environmental rules (say about the regrowth of resources) may be micro-specified (Epstein and Axtell, 1996). Hence, we specify the environment as macro/micro to signify its dual nature. In our conceptual framework, a CAS includes agents as well as their "Interpreted and Enacted Environment." This part of the environment is manifest in terms of the relevant task and institutional contexts with which the agents directly interact. The remaining part of the environment is outside the boundaries of the CAS and is referred to as the "External Environment." We assert that the boundary between the "External Environment" and the "Interpreted \& Enacted Environment" is dynamic (presented as dotted lines) such that, over time, agents interact with elements of the external environment through a sensemaking mechanism. The "Interpreted \& Enacted Environment" and "External Environment" blocks include facets such as resource distribution, the ruggedness of the landscape, and whether the environment is static or dynamic in nature.

Given that emergent system properties are an outcome of the interactions between agents and environment, it has a macro-specification. It covers the collective behavior and the level of self-organization in the system. As compared to the connectivity among agents that we include as part of the "Agents" block, the global patterns of connectivity 
within the system fall within the "Emergent System Properties" block in the model.

While it is of course possible to specify non-linear interactions among agents, or agents and the environment, the most relevant non-linear dynamics are those that emerge as system properties from the underlying interactions, not those coded into the initial specifications. The non-equilibrium, quasi-stable states, and path-dependent effects are part of the "Emergent System Properties" conceptual block.

The conceptual model presented in Figure 1 operates within a rule system, which represents the meso state within which the "Agents," "Environment," and "Emergent System Properties" are encased. It is important to note that micro and macro categories should be considered relative rather than absolute. We should have in mind a multi-scale picture comprising of micro-meso-macro states of a CAS.

\section{Figure 1: Conceptual Framework}

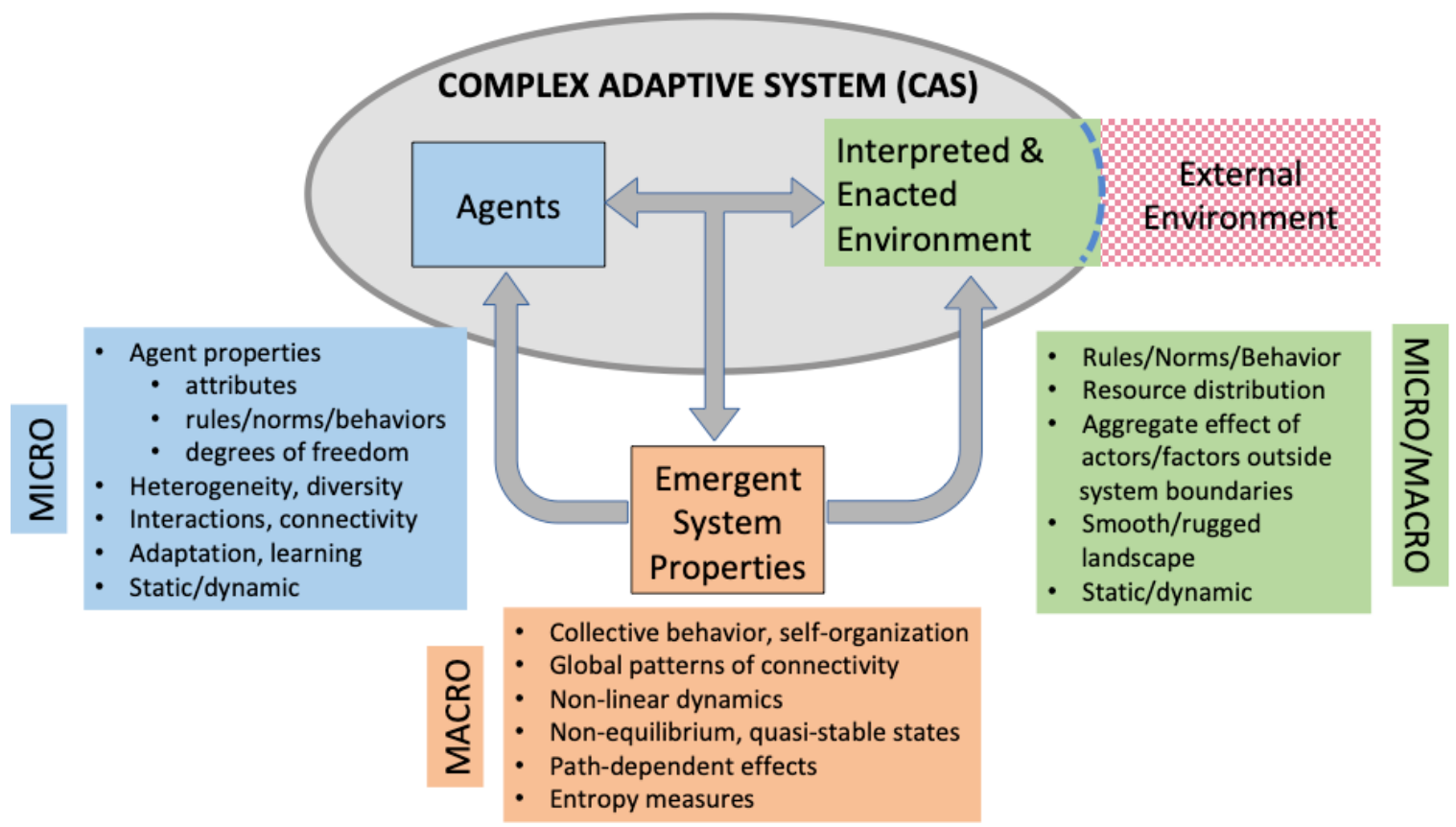




\section{Articles in this Special Issue}

Five articles made it through a rigorous review process to become part of this Special Issue. In the study titled, "An Empirical Investigation of Transaction Dynamics in Online Surplus Networks: A Complex Adaptive Systems Perspective,” Dhanorkar et al. used data from MNexchange.org, an Online Material and Waste Exchange (OMWE) and investigated how the complex OMWE surplus-driven supply network adapts to alter the likelihood of transactions between buyers and suppliers. The study considers node-level adaptation of searches for products over time that increases transaction success. In essence, it focuses on agent attributes, behavior, degrees of freedom, and adaptation as presented in Figure 1. At a dyadic level the adaptation takes agent interaction and level of heterogeneity into consideration. As shown in Figure 1, these aspects are integral part of agents in CAS. The study shows that homophilous relations facilitate negotiations and increase transaction success. It also captures the aspect of agent degree of freedom presented in Figure 1 in terms of buyer competition, history of the product in the market, and buyer's level of experience. At the network level the study focuses on emergent network properties of self-organization (Figure 1). The paper offers implications of adaptive behavior at the node level, dyadic level, and network level.

Using a sample of 4,189 process networks extracted from an environmental life cycle inventory database, in "Process Network Modularity, Commonality, and Greenhouse Gas Emissions,” Dooley et al. consider the impact of structural and functional characteristics of a product's process network on the network's collective greenhouse gas emissions. The study highlights the advantages of a modular network structure and the functional similarity between constituent unit processes. In line with the 
conceptualization in Figure 1, by considering process networks (the environment that is interpreted and enacted upon) as part of the CAS, the study examines how the network's structural and functional characteristics impact the network's performance.

In the paper titled, “Temporary De-Embedding Buyer-Supplier Relationships: A Complexity Perspective," Sting et al. examine the performance implications of relaxing embedded buyer-supplier relationships for a limited period of time. The paper focuses on the aspects of agent behavior, interactions, and dynamic adaptation as presented in Figure 1. It combines a longitudinal case study of the relationship between Nissan and a strategic, first-tier supplier with a computational simulation model using the search perspective from complexity theory. The findings emphasize the effects of frequency, duration, and intensity of de-embedding on supply chain performance.

In "Identifying Dynamical Instabilities in Supply Networks Using Generalized Modeling," Demirel et al. apply a Generalized Modeling approach and focus on the network of interactions between material flows to provide stability analyses of two contrasting real world networks, an industrial engine manufacturer and an industry-level network in the luxury goods sector. The study shines a spotlight on emergent system properties, specifically on the nonlinear dynamics and quasi-stable states of the system as shown in Figure 1. The article highlights the criticality of links with suppliers, cyclic motifs, and competing demands of different end products at specific nodes.

Finally, in "Modeling Supply Chain Adaptation for Disruptions: An Empirically Grounded Complex Adaptive Systems Approach,” Zuo et al. analyze a real-world supply chain network among 2,971 firms spanning 90 industry sectors. The study focuses on the interaction between environment and agent within the CAS as shown in Figure 1. It 
conceptualizes environment in terms of competition relationships within a supply chain network and, using an agent-based simulation model, shows firms' adaptive behavior for leveraging these relationships. The paper presents reactive and proactive adaptive strategies that a firm can leverage to reduce the negative effects of supply chain network disruptions.

\section{Future Directions}

The cascading nature of processes, decisions, and outcomes in OSCM can be effectively studied by taking the CAS perspective. The papers considered in this special issue focus on various aspects of the CAS framework as presented in Figure 1. Yet, several opportunities for furthering knowledge within this space. Operations and supply chain outcomes rely on certain search processes aimed at improving local performance of the firms in the network. A CAS perspective can unravel the search process and present a deeper understanding of how overall performance improvement can be achieved. It can be particularly useful to study indirect effects within several operations and supply chain problems where there is no obvious relationship between cause and effects. The CAS perspective can help in understanding the process as well as the outcome of pattern formation that are evident in many situations pertaining to OSCM. As an example, norms in buyer-supplier relationships take shape through a collective pattern that can be examined by considering the CAS perspective. The CAS perspective calls for considering part 'in vivo.' Investigating how changes in one part affect others and the behavior of the whole can help in assessing the inherent nature of CAS, such as supply networks. In this 
regard, this CAS perspective can help in further discerning how control and emergence operate in supply networks (Giannoccaro et al. 2018).

Consideration of structural contingency has a rich tradition in OSCM research (Ketokivi and Schroeder 2004; Flynn et al. 2010; Ketokivi and Choi 2014). Yet, in most cases, structure is viewed as a linear contingency variable. Studies adopting a complex systems perspective have shown that structure can also act as a nonlinear contingency. In their examination of scaling of cities, Bettencourt et al. (2010) considered the fundamental role of nonlinear agglomeration that is integral to the life history of cities. This helps in avoiding the conflation of general nonlinear effects (such as per capita income measures) that are common to all cities with local dynamics specific to each city (such as local events and policy). Similar considerations would help in disentangling the general and local effects within OSCM. Routines, replication, and inheritance form the cornerstone of several OSCM practices. The CAS perspective can help in better understanding how these aspects contribute towards short-term efficiency and long-term learning outcomes in organizations. Additionally, relaxation of the rationality assumptions can help in discerning the emergent properties of agents in OSCM contexts.

The study of complex systems and CAS utilizes several methodological approaches that can also be used effectively for studying issues in OSCM. For instance, latent space models and latent class models (e.g., stochastic block models) can be used to examine both the observed and unobserved structure of networks. The latent space model assumes that nodes are positioned in an R-dimensional latent space, and they tend to create edges to others that are closer in their latent positions (Kim et al. 2018). Due to this simple geometry-based assumption, these models can be utilized for interpreting 
relational networks within supply chain management. The stochastic block models assume that the nodes of the network are partitioned into several unobserved (latent) classes (or blocks). These models can take a form in which the membership of nodes are known a-priori with a goal of estimating a matrix of edge probabilities (Holland et al. 1983 ) or can involve a posteriori block modeling where the objective is to estimate the matrix of edge probabilities and the memberships simultaneously (Snijders and Nowicki 1997; Nowicki and Snijder 2001). Within the OSCM field, conceptual and methodological developments in the area of design structure matrix (DSM) incorporate some of the aspects of these block models to examine the underlying complexity within the contexts of product design and development, project management, and systems engineering (Browning 2016; Lévárdy and Browning 2009). Additional efforts in this direction have the potential to shed new insights.

Over the years, these stochastic block models have been enhanced to include mixed-membership stochastic block models that can accommodate multi-faceted nodes playing different latent roles (Airoldi et al. 2008) and degree-corrected stochastic block models that help to capture the heterogeneity of node degrees (i.e., the number of edges the nodes can have to other nodes) within communities (Karrer and Newman 2011). These enhancements provide a good methodological toolset to examine the bipartite, weighted, and hierarchical community structures as well as community structures with metadata that are observed in OSCM. The development of dynamic, stochastic block models in the past decade (e.g., Yang et al. 2011) paves the way for studying operations and supply chain networks that evolve over time. Additionally, as mentioned earlier in 
the paper, Shannon-Jensen divergence analysis can be used to account explicitly for diversity of connection among agents or between agents and environment in the CAS.

Entropy has been a prominent concept within the study of complex systems. The concept is based on the second law of thermodynamics, which states that without outside intervention heat always flows from a warm body to a body with lower temperature. It leads to the general assertion that a closed system always evolves towards its most probable macrostate - i.e., one in which its entropy is maximized, which implies that the entropy acts as an attractor (Boltzmann, 1877). The concept of entropy extends to the field of information theory, a branch of probability and statistics, which studies the amount of information and everything related to it such as channels, data compression, and cryptography (Shannon, 1948). The basic conclusion is that information is a measurable quantity and the quantitative expression for the amount of information is isomorphic to negative entropy (Shannon, 1948; Wiener, 1961). This concept can be usefully applied in OSCM contexts by considering the energy that is invested to obtain, process, store, and communicate information. For example, Smunt and Ghose (2016) examined manufacturing system performance by considering entropy flow dominance. The single measure aggregates information embedded in the routings of all products within a system.

Studies in organization science have considered turbulence by operationalizing it to be a part of the environment (Siggelkow and Rivkin, 2005). In addition to such conceptualizations, use of the concept of Reynold's number can provide interesting methodological directions. The Reynold's number, measured by dividing inertia by viscosity, is a non-dimensional number that predicts when fluid changes from laminar to 
turbulent flow. A Reynolds number less than 2000 indicates laminar flow and a value over 2300 indicates turbulent flow. In between these values, the fluid is considered to be unstable and might flow in either state. This idea can be used in organizational settings to capture the chaotic flow of information. For instance, complex new product development places high information processing needs on managers. A metric that captures the turbulence in these information flows may alert organizations to imminent project failures (Fyall 2002).

Operational analysis has tended to take a reductionist approach in the study of systems. While it generates important insights, studies in condensed matter physics (in particular, magnetism and superconductivity) have revealed that collective behavior is not a trivial detail of its constituent parts; instead, it requires a profound theory (Anderson 1972; Anderson 2018). In research pertaining to OSCM, we need analysis at multiple scales (at least at micro and macro scale). As an example, in their examination of lean practices in Lockheed Martin's production system for the F- 22 aircraft, Browning and Heath (2009) asserted the need for considering waste and value in a different way. They emphasized that, while consideration of individual tasks and their interactions shed important light on the nature of waste and value, there is a need to account for the macrolevel system behavior. Specifically, they noted, "Value is an emergent property of a complex process that cannot be completely decomposed and allocated to the process's constituent tasks and interactions" (p. 40). The ability of the CAS perspective to undertake a multi-scale examination of a system offers a unique advantage for studying several pertinent operational and supply chain management issues, since it 
allows close monitoring of system-level behavior that can propagate between micro and macro levels.

The current business environment presents a tremendous opportunity for conducting empirical analysis with large sets of data that are being generated and collected by means enterprise information systems, point-of-sale technologies, social media, and blockchains, among others. Much of the empirical research in the field has been focused on understanding average behavior: the CAS-based empirical techniques can help in going beyond investigations of average behavior to the identification of longtail distributions and extreme events (Albeveria et al. 2006). Several datasets in the operations and supply chain arena are likely nonlinear in nature. Yet, we use linear methods to interpret regular structure in the datasets, with an assumption that the intrinsic dynamics of the system are governed by the linear paradigm that small causes lead to small effects. The assumption of linearity attributes all irregular behavior of the system to random external inputs. In fact, irregular behavior in a system can also be due to purely deterministic effects, which are also unaccounted for in linear models. It is important to capture the underlying information in the irregular datasets generated in business environments using the phase space representation instead of relying only on a time or frequency domain approach. Additionally, the sensitivity of nonlinear dynamical systems to changes in the initial conditions requires characterization of dynamical instability and the Lyapunov exponent. To study these from a time series standpoint, the CAS paradigm offers methodological directions in terms of application of attractor geometry, fractal dimensions, and a more complex set of analytical techniques (see Kantz and Schreiber 2004). 
We believe that the highly interconnected nature of contemporary operations and supply chains will enhance the importance of the CAS perspective in coming years. This special issue presents research papers that examine a broad range of topics, yet we believe that this is just a small snapshot of the many possible research questions that may be addressed effectively with a CAS perspective. We hope that the conceptual framework presented in this paper, the proposed theoretical and methodological directions, and the papers included within this special issue will prompt renewed and broad-based research interest in investigations pertaining to complexity, adaptation, and emergent behavior in OSCM. 


\section{References}

Airoldi, E.M., Blei, D.M., Fienberg, S.E. and Xing, E.P., 2008. Mixed membership stochastic blockmodels. Journal of Machine Learning Research, 9(Sep), pp.1981-2014.

Albeverio, S., Jentsch, V. and Kantz, H. eds., 2006. Extreme events in nature and society. Springer Science \& Business Media.

Alderson, W. 1965. Dynamic marketing behavior; A functionalist theory of marketing. Homewood, IL: R.D. Irwin.

Alhadeff-Jones, M., 2008. Three generations of complexity theories: Nuances and ambiguities. Educational Philosophy and Theory, 40(1), pp.66-82.

Altay, N. and Pal, R., 2014. Information diffusion among agents: implications for humanitarian operations. Production and Operations Management, 23(6), pp.1015-1027.

Anderson, P.W., 1972. More is different. Science, 177(4047), pp.393-396.

Anderson, P. 1999. Complexity theory and organization science. Organization Science, 10, 216-232.

Anderson, P.W., 2018. Basic notions of condensed matter physics. CRC Press.

Arthur, W. B. 1995. Complexity in economic and financial markets: Behind the physical institutions and technologies of the marketplace lie the beliefs and expectations of real human beings. Complexity, 1(1), 20-25.

Axtell, R. A. 2003. Toward behavioral realism in retirement models: From micro simulation to agent-based modeling. Presentation made at the Conference on Improving Social Insurance Programs, University of Maryland, College Park, MD.

Azadegan, A., Patel, P.C., Zangoueinezhad, A. and Linderman, K., 2013. The effect of environmental complexity and environmental dynamism on lean practices. Journal of Operations Management, 31(4), pp.193-212.

Barabási, A.L. and Albert, R., 1999. Emergence of scaling in random networks. Science, 286(5439), pp.509-512.

Barrat, A., Barthelemy, M., Pastor-Satorras, R. and Vespignani, A., 2004. The architecture of complex weighted networks. Proceedings of the national academy of sciences, 101(11), pp.3747-3752.

Bascompte, J., Jordano, P., Melián, C.J. and Olesen, J.M., 2003. The nested assembly of

plant-animal mutualistic networks. Proceedings of the National Academy of Sciences, 100(16), pp.9383-9387. 
Basole, R. C., \& Bellamy, M. A. (2014). Supply network structure, visibility, and risk diffusion: A computational approach. Decision Sciences, 45(4), 753-789.

Bettencourt, L. M., Lobo, J., Strumsky, D., \& West, G. B. 2010. Urban scaling and its deviations: Revealing the structure of wealth, innovation and crime across cities. PloS one, 5(11), e13541.

Boal, K.B. and Schultz, P.L., 2007. Storytelling, time, and evolution: The role of strategic leadership in complex adaptive systems. The leadership quarterly, 18(4), pp.411-428.

Bode, C. and Wagner, S.M., 2015. Structural drivers of upstream supply chain complexity and the frequency of supply chain disruptions. Journal of Operations Management, 36, pp.215-228.

Boltzmann, L., 1877. Über die Beziehung zwischen dem zweiten Hauptsatze des mechanischen Wärmetheorie und der Wahrscheinlichkeitsrechnung, respective den Sätzen über das Wärmegleichgewicht. Kk Hof-und Staatsdruckerei.

Bozarth, C., \& McDermott, C. (1998). Configurations in manufacturing strategy: a review and directions for future research. Journal of Operations Management, 16(4), 427439.

Bozarth, C.C., Warsing, D.P., Flynn, B.B. and Flynn, E.J., 2009. The impact of supply chain complexity on manufacturing plant performance. Journal of Operations Management, 27(1), pp.78-93.

Braha, D., Yaneer, B.-Y. 2007. The statistical mechanics of complex product development: Empirical and analytical results. Management Science, 53, 1127-1145.

Brock, W.A. and Hommes, C.H., 1998. Heterogeneous beliefs and routes to chaos in a simple asset pricing model. Journal of Economic dynamics and Control,22(8-9), pp.1235-1274.

Browning, T.R., 2016. Design structure matrix extensions and innovations: a survey and new opportunities. IEEE Transactions on Engineering Management, 63(1), pp.27-52.

Browning, T.R. and Heath, R.D., 2009. Reconceptualizing the effects of lean on production costs with evidence from the F-22 program. Journal of Operations Management, 27(1), pp.23-44.

Browning, T.R. and Ramasesh, R.V., 2007. A survey of activity network-based process models for managing product development projects. Production and operations management, 16(2), pp.217-240. 
Choi, K., Narasimhan, R. and Kim, S.W., 2012. Postponement strategy for international transfer of products in a global supply chain: A system dynamics examination. Journal of operations Management, 30(3), pp.167-179.

Choi, T. Y., Dooley, K. J., Rungtusanatham, M. 2001. Supply networks and complex adaptive systems: Control versus emergence. Journal of Operations Management, 19, 351-366.

Choi, T.Y. and Hong, Y., 2002. Unveiling the structure of supply networks: case studies in Honda, Acura, and DaimlerChrysler. Journal of Operations Management, 20(5), pp.469-493.

Choi, T. Y., Krause, D. R. 2006. The supply base and its complexity: Implications for transaction costs, risks, responsiveness, and innovation. Journal of Operations Management, 24, 637-652.

Cilliers, P. 2002. Complexity and postmodernism: Understanding complex systems. routledge.

Closs, D.J., Jacobs, M.A., Swink, M. and Webb, G.S., 2008. Toward a theory of competencies for the management of product complexity: six case studies. Journal of Operations Management, 26(5), pp.590-610.

Crutchfield, J. P. (2012). Between order and chaos. Nature Physics, 8(1), 17.

Daft, R.L. and Weick, K.E., 1984. Toward a model of organizations as interpretation systems. Academy of Management Review, 9(2), pp.284-295.

Dieckmann, U. and Law, R., 1996. The dynamical theory of coevolution: a derivation from stochastic ecological processes. Journal of mathematical biology, 34(5-6), pp.579612.

Dopfer, K., Foster, J. and Potts, J., 2004. Micro-meso-macro. Journal of evolutionary economics, 14(3), pp.263-279.

Epstein, J. M., Axtell, R. 1996. Growing artificial societies: Social science from the bottom up. MIT Press, Cambridge, Mass.

Ethiraj S. K., Levinthal D. A. 2004. Modularity and innovation in complex systems. Management Science 50(2): 159-173.

Ethiraj, S. K. 2007. Allocation of inventive effort in complex product systems. Strategic Management Journal 28: 563-584. 
Fine, C.H. 2000. Clockspeed-based strategies for supply chain design. Production and operations management, 9(3), pp.213-221.

Flynn, B. B., Huo, B., \& Zhao, X. 2010. The impact of supply chain integration on performance: A contingency and configuration approach. Journal of operations management, 28(1), 58-71.

Fransoo, J.C. and Wiers, V.C., 2006. Action variety of planners: Cognitive load and requisite variety. Journal of Operations Management, 24(6), pp.813-821.

Fyall, M., 2002. When project information flow becomes turbulent: toward an organizational reynolds number (Vol. 138). CIFE Technical Report.

Gell-Mann, M., 1992. Complexity and complex adaptive systems. In Santa Fe Institute Studies in the Sciences of Complexity Proceedings, Vol. 11, pp. 177-177. AddisonWesley Publishing Co.

Gell-Mann, M., 2002. What is complexity?. In Complexity and industrial clusters (pp. 13-24). Physica-Verlag HD.

Giannoccaro, I., Nair, A., Choi, T. 2018. The impact of control and complexity on supply network performance: An empirically informed investigation using NK simulation analysis. Decision Sciences, 49(4), 625-659.

Gligor, D.M., Esmark, C.L. and Holcomb, M.C., 2015. Performance outcomes of supply chain agility: when should you be agile? Journal of Operations Management, 33, pp.7182.

Grimm, V. 1999. Ten years of individual-based modelling in ecology: What have we learned and what could we learn in the future. Ecological Modelling, 115, 129-148.

Grimm, V., Revilla, E., Berger, U., Jeltsch, F., Mooij, W.M., Railsback, S.F., Thulke, H. H., Weiner, J., Wiegand, T., DeAngelis, D.L 2005. Pattern-oriented modeling of agentbased complex systems: lessons from ecology. Science 310: 987-991.

Halstrøm, P. L., \& Galle, P. (2015). Design as co-evolution of problem, solution, and audience. Artifact: Journal of Design Practice, 3(4), 3-1.

Handley, S.M. and Benton Jr, W.C., 2013. The influence of task-and location-specific complexity on the control and coordination costs in global outsourcing relationships. Journal of Operations Management, 31(3), pp.109-128.

Harvey, J., 2016. Professional service supply chains. Journal of operations management, 42, pp.52-61. 
Holland, J.H., 1995. Hidden order: how adaptation builds complexity. Reading, MA: Perseus.

Holland, P.W., Laskey, K.B. and Leinhardt, S., 1983. Stochastic blockmodels: First steps. Social networks, 5(2), pp.109-137.

Holweg, M. and Pil, F.K., 2008. Theoretical perspectives on the coordination of supply chains. Journal of operations management, 26(3), pp.389-406.

Hwarng, H.B. and Xie, N., 2008. Understanding supply chain dynamics: A chaos perspective. European Journal of Operational Research, 184(3), pp.1163-1178.

Jacobs, M.A. and Swink, M., 2011. Product portfolio architectural complexity and operational performance: Incorporating the roles of learning and fixed assets. Journal of Operations Management, 29(7-8), pp.677-691.

Jayanthi, S., \& Sinha, K. K. 1998. Innovation implementation in high technology manufacturing: A chaos-theoretic empirical analysis. Journal of Operations Management, 16(4), 471-494.

Jokela, J. 2010. Transgenerational immune priming as cryptic parental care. Journal of animal ecology, 79(2), 305-307.

Kadirov, D. and Varey, R.J., 2011. Symbolism in marketing systems. Journal of Macromarketing, 31(2), pp.160-171.

Kantz, H. and Schreiber, T., 2004. Nonlinear time series analysis (Vol. 7). Cambridge university press.

Karrer, B. and Newman, M.E., 2011. Stochastic blockmodels and community structure in networks. Physical review E, 83(1), p.016107.

Kauffman, S.A. and Johnsen, S., 1991. Coevolution to the edge of chaos: coupled fitness landscapes, poised states, and coevolutionary avalanches. Journal of theoretical biology, 149(4), pp.467-505.

Ketokivi, M., \& Choi, T. 2014. Renaissance of case research as a scientific method. Journal of Operations Management, 32(5), 232-240.

Ketokivi, M. A., \& Schroeder, R. G. (2004). Strategic, structural contingency and institutional explanations in the adoption of innovative manufacturing practices. Journal of Operations Management, 22(1), 63-89.

Kim, Y., Chen, Y.S. and Linderman, K., 2015. Supply network disruption and resilience: A network structural perspective. Journal of operations Management, 33, pp.43-59. 
Kim, Y., Choi, T. Y., Yan, T., \& Dooley, K. (2011). Structural investigation of supply networks: A social network analysis approach. Journal of Operations Management, 29(3), $194-211$

Kim, B., Lee, K. H., Xue, L., \& Niu, X. 2018. A review of dynamic network models with latent variables. Statistics Surveys, 12, 105-135.

Kovach, J.J., Hora, M., Manikas, A. and Patel, P.C., 2015. Firm performance in dynamic environments: The role of operational slack and operational scope. Journal of Operations Management, 37, pp.1-12.

Lang, M., Deflorin, P., Dietl, H., \& Lucas, E. 2014. The impact of complexity on knowledge transfer in manufacturing networks. Production and Operations Management, 23(11), 1886-1898.

Laughlin, R.B. and Pines, D., 2000. The theory of everything. Proceedings of the National Academy of Sciences, 97(1), pp.28-31.

Lee, M. E. 1997. From enlightenment to chaos. In R. A. Eve, S. Horsfall, \& M. E. Lee (Eds.), Chaos, complexity and sociology (pp. 15-29). Thousand Oaks, CA: Sage.

Lehn, J.M., 2013. Perspectives in chemistry - steps towards complex matter. Angewandte Chemie International Edition, 52(10), pp.2836-2850.

Lévárdy, V. and Browning, T.R., 2009. An adaptive process model to support product development project management. IEEE Transactions on Engineering Management, 56(4), pp. 600-620.

Levinthal, D. A. 1997. Adaptation on rugged landscapes. Management Science, 43, 934951.

Levinthal, D. A., Warglien, M. 1999. Landscape design: Designing for local action in complex worlds. Organization Science, 10, 342-357.

Li, C. B., Yang, H., \& Komatsuzaki, T. (2008). Multiscale complex network of protein conformational fluctuations in single-molecule time series. Proceedings of the National Academy of Sciences, 105(2), 536-541.

Lomi, A., Pattison, P. 2006. Manufacturing relations: an empirical study of the organization of production across multiple networks. Organization Science, 17, 313 332.

Matos, S. and Hall, J., 2007. Integrating sustainable development in the supply chain: The case of life cycle assessment in oil and gas and agricultural biotechnology. Journal of Operations Management, 25(6), pp.1083-1102. 
May, R. M. (2001). Stability and complexity in model ecosystems (Vol. 6). Princeton university press.

May, R.M., Gupta S. \& McLean, A.R. 2001. Infectious disease dynamics: what characterizes a successful invader? Phil. Trans. R. Soc. Lond. B 356: 901-910.

McGahan, A.M., Argyres, N. and Baum, J.A., 2004. Context, technology and strategy: forging new perspectives on the industry life cycle. In Business strategy over the industry lifecycle (pp. 1-21). Emerald Group Publishing Limited.

Miller, J. H., \& Page, S. E. (2007). Complex adaptive systems. Princeton, NJ: Princeton University Press.

Nair, A., Narasimhan, R., Choi. T. 2009. Supply Networks as a Complex Adaptive System: Toward Simulation-Based Theory Building on Evolutionary Decision Making. Decision Sciences, 40(4), 783-815.

Nair, A., \& Vidal, J. M. (2011). Supply network topology and robustness against disruptions-an investigation using multi-agent model. International Journal of Production Research, 49(5), 1391-1404.

Nair, A., Narasimhan, R., Bendoly, E. 2011. Co-opetitive Buyer-Supplier Relationship: An Investigation of Bargaining Power, Relational Context, and Investment Strategies. Decision Sciences, 42(1), 93-127.

Narasimhan, R., Nair, A., Griffith, D., Arlbjørn, J., Bendoly, E. 2009. Lock-in situations in supply chains: Social exchange theoretic study of sourcing arrangements in powerbased buyer-supplier relationship. Journal of Operations Management, Vol. 27, No. 5, 374-389.

Nilsson, F., Darley, V. 2006. On complex adaptive systems and agent-based modeling for improved decision-making in manufacturing and logistics settings. International Journal of Operations and Production Management, 26, 1351-1373.

Nowicki, K. and Snijders, T.A.B., 2001. Estimation and prediction for stochastic blockstructures. Journal of the American statistical association, 96(455), pp.1077-1087.

Olesen, J.M., Bascompte, J., Dupont, Y.L. and Jordano, P., 2007. The modularity of pollination networks. Proceedings of the National Academy of Sciences, 104(50), pp.19891-19896.

Papo, D., Buldú, J.M., Boccaletti, S. and Bullmore, E.T., 2014. Complex network theory and the brain. Philosophical Transactions of the Royal Society B: Biological Sciences, 369(1653). 
Pathak, S., Day, J. M., Nair, A., Sawaya, W., Kristal, M. 2007. Complexity and Adaptivity in Supply Networks: Building Supply Network Theory Using a Complex Adaptive Systems Perspective. Decision Sciences Journal, Vol. 38, Iss. 4., 547-580.

Pathak, S.D., Wu, Z. and Johnston, D., 2014. Toward a structural view of co-opetition in supply networks. Journal of Operations Management, 32(5), pp.254-267.

Patterson, B. D. and Atmar, W. 1986. Nested subsets and the structure of insular mammalian faunas and archipelagos. Biol. J. Linn. Soc. 28: 65-82.

Ramasesh, R.V. and Browning, T.R., 2014. A conceptual framework for tackling knowable unknown unknowns in project management. Journal of Operations Management, 32(4), pp.190-204.

Rivkin, J.W., Siggelkow, N. 2007. Patterned interactions in complex systems: Implications for exploration. Management Science, 53, 1068-1085.

Rosso, O. A., Teresa, M., Larrondo, H. A., Kowalski, A., \& Plastino, A. (2013). Generalized statistical complexity: A new tool for dynamical systems. Concepts and Recent Advances in Generalized Information Measures and Statistics; Kowalski, AM, Rossignoli, RD, Curado, EMF, Eds.

Ruelle, D. (1980). Measures describing a turbulent flow. Annals of the New York Academy of Sciences, 357(1), 1-9.

Saavedra, S., Reed-Tsochas, F., Uzzi B. 2008. Asymmetric disassembly and robustness in declining networks. Proceedings of the National Academy of Sciences 105(43): 1646616471.

Saavedra, S., Reed-Tsochas, F., Uzzi, B. 2009. A simple model of bipartite cooperation for ecological and organizational networks. Nature 457: 463-466.

Schelling, T.C. 1971. Dynamic models of segregation. Journal of Mathematical Sociology, ISSN 1545-5874, $1: 143-186$.

Schelling, T.C., 2006. Micromotives and macrobehavior. WW Norton \& Company.

Seifert, M., Siemsen, E., Hadida, A. L., \& Eisingerich, A. B. (2015). Effective judgmental forecasting in the context of fashion products. Journal of Operations Management, 36, 33-45.

Shannon, C.E., 1948. A mathematical theory of communication. Bell system technical journal, 27(3), pp.379-423. 
Shapiro, S.J., 1964. The survival concept and the nonprofit behavior system. In Theory in Marketing, ed. R. Cox, W. Alderson, and S. J. Shapiro. Homewood, IL: Richard D. Irwin. Simon, H. A. (1992). What is an "explanation" of behavior? Psychological science, 3(3), 150-161.

Simon, H. A. (2000). Can there be a science of complex systems. Unifying themes in complex systems, 1, 3-14.

Siggelkow, N. and Rivkin, J.W., 2005. Speed and search: Designing organizations for turbulence and complexity. Organization Science, 16(2), pp.101-122.

Smunt, T.L. and Ghose, S., 2016. An Entropy Measure of Flow Dominance for Predicting Operations Performance. Production and Operations Management, 25(10), pp.1638-1657.

Snijders, T.A. and Nowicki, K., 1997. Estimation and prediction for stochastic blockmodels for graphs with latent block structure. Journal of classification, 14(1), pp.75-100.

Strogatz, S.H., 2001. Exploring complex networks. Nature, 410(6825), p.268.

Tangpong, C., Hung, K. T., \& Li, J. (2014). Agent-system co-development in supply chain research: Propositions and demonstrative findings. Journal of Operations Management, 32(4), 154-174.

Tenhiälä, A., 2011. Contingency theory of capacity planning: The link between process types and planning methods. Journal of Operations Management, 29(1-2), pp.65-77.

Thomas, J.B., Clark, S.M. and Gioia, D.A., 1993. Strategic sensemaking and organizational performance: Linkages among scanning, interpretation, action, and outcomes. Academy of Management journal, 36(2), pp.239-270.

Urda, J. and Loch, C.H., 2013. Social preferences and emotions as regulators of behavior in processes. Journal of Operations Management, 31(1-2), pp.6-23.

van der Leeuw, S.E., McIntosh, R.J., Tainter, J.A. and McIntosh, S.K., 2000. The way the wind blows: climate change, history and human action. New York: Columbia University Press.

Van Valen, L., 1973. A new evolutionary law. Evolutionary Theory, 1, pp.1-30.

Vanpoucke, E., Vereecke, A. and Wetzels, M., 2014. Developing supplier integration capabilities for sustainable competitive advantage: A dynamic capabilities approach. Journal of Operations Management, 32(7-8), pp.446-461. 
VanWinkle,W., Rose, K. A., Chambers, R. C. 1993. Individual-based approach to fish population dynamics: An overview. Transactions of the American Fisheries Society, 122, $397-403$.

Verma, D., Mishra, A. and Sinha, K.K., 2011. The development and application of a process model for R\&D project management in a high tech firm: A field study. Journal of Operations Management, 29(5), pp.462-476.

Von Bertalanffy, L., 1972. The history and status of general systems theory. Academy of Management Journal, 15(4), pp.407-426.

Wagner, S.M., Kurpjuweit, S. and Choi, T.Y., 2017. Managing Startup Suppliers. CAPS Research.

Wang, W., Chen, Y. and Huang, J., 2009. Heterogeneous preferences, decision-making capacity, and phase transitions in a complex adaptive system. Proceedings of the National Academy of Sciences, 106(21), pp.8423-8428.

Weaver, W. 1948. Science and complexity. American Scientist 36, 536-544.

Wiener, N., 1961. Cybernetics or Control and Communication in the Animal and the Machine (Vol. 25). MIT press.

Wilhelm, M.M., Blome, C., Bhakoo, V. and Paulraj, A., 2016. Sustainability in multi-tier supply chains: Understanding the double agency role of the first-tier supplier. Journal of Operations Management, 41, pp.42-60.

Williams, B.D., Roh, J., Tokar, T. and Swink, M., 2013. Leveraging supply chain visibility for responsiveness: The moderating role of internal integration. Journal of Operations Management, 31(7-8), pp.543-554.

Wosniack, M.E., da Luz, M.G.E. and Schulman, L.S., 2017. Punctuated equilibrium as an emergent process and its modified thermodynamic characterization. Journal of theoretical biology, 412, pp.113-122.

Yan, T., Choi, T.Y., Kim, Y. and Yang, Y., 2015. A theory of the nexus supplier: A critical supplier from a network perspective. Journal of Supply Chain Management, 51(1), pp.52-66.

Yang, T., Chi, Y., Zhu, S., Gong, Y. and Jin, R., 2011. Detecting communities and their evolutions in dynamic social networks - a Bayesian approach. Machine learning, 82(2), pp.157-189. 